\title{
Food System Dynamics in Rural Environments and Health Benefits of the Mediterranean Diet \\ Azzini $\mathrm{E}^{1, *}$, Barnaba $\mathrm{L}^{1}$, Intorre $\mathrm{F}^{1}$, Ciarapica $\mathrm{D}^{1}$, Verrascina $\mathrm{M}^{2}$, Zanetti $\mathrm{B}^{2}$, Venneria $\mathrm{E}^{1}$, Foddai $\mathrm{MS}^{1}$, Maiani $\mathrm{F}^{1}$, Monteleone $\mathrm{A}^{2}$ and Polito $\mathbf{A}^{1, *}$ \\ ${ }^{1}$ Council for Agricultural Research and Agricultural Economics Analysis Research Centre for Food and Nutrition, Italy \\ ${ }^{2}$ Council for Agricultural Research and Agricultural Economics Analysis Research Centre for Politics and Bioeconomy, Italy
}

\begin{abstract}
Background: The changing in food system dynamics are strictly correlated to human nutritional status. The Italian Mediterranean eating habits is the result of traditions, local foods, biodiversity, nutrition, people, culture, economy and sustainability strongly connected.

The aim of the present study was to examine the interdependencies of local food system dynamics and health benefits of the Mediterranean Diet (MD) on cardiovascular disease prevention in rural areas within the Majella National Park. For this purpose, were carried out different assessments including socioeconomic, market dynamics and nutritional indicators.
\end{abstract}

Methods: A pilot study was conducted on 99 healthy subjects aged 35-70 years. For the survey on local production and the type of distribution of local food products, a "one to one" questionnaire was carried out among farmers, retailers and commercial dealers. Adherence to the Mediterranean food pattern was evaluated by a semi-quantitative food frequency, using the Mediterranean Dietary Serving Score (MDSS).Anthropometric measurements and biochemical analyses of nutritional interest were performed according to the standardized procedure. Cardiovascular risk score was calculated according to the CUORE algorithm.

Results: The results of socio-economic assessment within selected municipalities highlighted two clearly distinct areas. A first area with higher presence of agricultural activities, while in the second location were present globalized production activities and eating habits like those in "urban" municipalities. Eating local was mainly determined by local awareness of products that ensure the purchase of authentic local produce with better organoleptic properties. The nutritional assessment in the two different socioeconomic areas highlighted a significant difference in the adherence to the Mediterranean food pattern by MDSS points $(\mathrm{p}=0.002)$ and significant reduction by at least $3 \%$ for cardiovascular risks $(\mathrm{p}=0.0009)$.

Conclusion: This pilot investigation confirmed the role of the socio-environmental and market dynamics in determining the population-level dietary patterns and eating behaviours in the prevention of human health.

\section{Introduction}

The effects of dietary intake and possible impacts on nutritional imbalances could be explained studying links between food system dynamics and human nutrition. As underlined by Ruben et al. [1] the understanding of the structure of a food system and its dynamics changes over time and space in relation to predefined social, environmental or distributional goals. According to the FAO [2], the definition of sustainable diets recognizes the interdependencies among food production and consumption, nutrients needs and dietary guidelines in addition to the link between human wellbeing and ecosystem change. Reynolds et al. [3] reviewed that several studies, but not all, achieved environmental benefits by reducing consumption of animal-based foods and increased consumption of fruit and vegetables, probably due to the similar levels of environmental impacts in reducing land and water resources. On the other hand, Vieux et al. [4] found that when meat was is calorically replaced by plant-based products there was a null effect, or even increased environmental impact because of the excessive amount of vegetable substitutes needed to replace animal proteins and calories. This reflects a dietary pattern not far from the Italian Mediterranean eating habits, a lifestyle of shared knowledge that is the result of a particular environmental historical multifaceted geographic region, in which traditions, local foods, biodiversity, nutrition, people, culture, economy and sustainability are strongly connected. Many rural areas of the Italian agricultural system are strongly characterized by

\section{Publication History:}

Received: April 04, 2020

Accepted: May 06, 2020

Published: May 08, 2020

\section{Keywords:}

Dietary patterns, Eating behaviours, Market dynamics, CVD risk, Human health local smaller productions achieved through techniques based on the historical and cultural traditions of that specific territory, manifested only in that specific area [5]. The modern food producing system has provided wider market opportunities for regional food products but, at the same time, led to a significant drop in the importance of local markets and, consequently, to a change for the worse in traditional nutritional behaviours of local populations. The nutritional quality of the foods available affects the health of people and the protective role of the Mediterranean Diet (MD) has been largely demonstrated [6], especially in diet related non-communicable diseases, mainly in cardiovascular risk prevention. Dontaset al. [7] reported the benefits from the adoption of a Mediterranean-based dietary pattern. Risks posed for cardiovascular disease were significantly lower among Greek "Corresponding Author: Dr. Elena Azzini, Council for Agricultural Research and Agricultural Economics Analysis Research Centre for Food and Nutrition, Italy; E-mail: elena.azzini@crea.gov.it

"Corresponding Author: Dr. Angela Polito, Council for Agricultural Research and Agricultural Economics Analysis Research Centre for Food and Nutrition, Italy; E-mail: angela.polito@crea.gov.it

Citation: Azzini E, Barnaba L, Intorre F, Ciarapica D, Verrascina M, et al. (2020) Food System Dynamics in Rural Environments and Health Benefits of the Mediterranean Diet. Int J Clin Nutr Diet 6: 151. doi: https://doi.org/10.15344/2456$8171 / 2020 / 151$

Copyright: (C) 2020 Azzini et al. This is an open-access article distributed under the terms of the Creative Commons Attribution License, which permits unrestricted use, distribution, and reproduction in any medium, provided the original author and source are credited. 
people living in rural areas as opposed to those living in urban or semi-rural environments. The Moli-sani study in Italy [8] identified a substantial shift from the MD to less traditional diets in those persons belonging to lower socioeconomic classes, thus leading these people to lose key dietary factors in cardiovascular risk protection.

Considering the above-mentioned reports, the aim of the present study is to examine the interdependencies of local food system dynamics and the health benefits of the MD on cardiovascular disease prevention in rural areas within the Majella National Park.

\section{Materials \& Method} characteristics of areas proposed by the National Strategy Plan for Rural Development (PSN) (Art.11, EU Reg.1698/2005) a restricted area within the Majella National Park has been selected for this study. It has been carried out in five municipalities (Montenerodomo, Pizzoferrato, Gamberale, Lama deiPeligniand Pennapiedimonte) located in the province of Chieti in the Abruzzo region. The research was organized into two specific fields of interest: the socioeconomic classes of the subjects under study and the repercussion of the same on their general health and wellbeing. The detailed methodologies are described elsewhere [9]. Consumption habits were studied through two surveys aimed at defining the links among the production sector, local trade and consumer demands.

\section{Market dynamics assessment of local food products}

In order to carry out a survey on local production and the type of distribution of local food products, a "one to one" questionnaire was carried out among farmers, retailers and commercial dealers in the municipalities under study. The questionnaire was divided into three parts. The first part focused on the type of sales outlet available for the purpose of identifying the specific nature of the sales outlet (e.g. farm/farm holiday, general grocery store, dairy products shop, butchers, etc.) and consequently the commercial environment in which the food products are offered to consumers as well as the position occupied by the sales outlet itself in the supply chain and thus whether the same operated as a direct seller or as an intermediary. The second part of the questionnaire was devoted to investigating the way in which the products sold were supplied and the reasons for which the consumer's choice was made, as well as the seller's perception as to what guided or attracted the local population with regard to purchasing local products. Finally, the third part of the questionnaire aimed at identifying the type of food products habitually bought by the local population and to what extent these products formed part of the traditional local food produce heritage.

\section{Nutritional assessment}

Study on the consumption and purchases of local populations and the consequent nutritional effects was carried out. 198 healthy free-living volunteers (61 males and 137 females), aged 18-86 years were enrolled for the survey; a sub-sample of 99 subjects aged 3570 years is selected for this pilot study. Following a detailed remote clinical assessment, the volunteers were selected based on the absence of pathologies potentially interfering with the parameters studied, the absence of ascertained viral infections, allergies and food intolerances. recruited subjects a high percentage of male volunteers chose not to join the study. A complete clinical check-up including a full medical
By cross-referencing territorial statistical data and socio-economic Subjects who did not meet these criteria were excluded and among the

assessment was performed on all subjects as well as assessment of drug use and blood pressure. In particularly, blood pressure was assessed by digital blood pressure monitor (Omron M1) clinically validated to ensure accuracy, in accordance with the protocol described by Pickering et al. [10], James \& Gerber [11] and Muntneret al.[12]. Aquestionnaire on lifestyle and a semi-quantitative food frequency questionnaire (FFQ) were administered by qualified interviewers. In addition, anthropometric measurements were performed and blood tests carried out for biochemical analyses of nutritional interest. The lifestyle questionnaire consisted of a package of questions on sociodemographic information, smoking habits and alcohol consumption. Educational levels were placed into three categories: low (primary schooling); medium (secondary schooling); high (university studies). Adherence to the Mediterranean food pattern was evaluated by a semi-quantitative food frequency, using the Mediterranean Dietary Serving Score (MDSS). This specific questionnaire is based on the latest update of the Mediterranean Diet Pyramid [13]. Briefly, three points were scored for the recommended intake of foods that should be present in every meal (fruit, vegetables, olive oil, and cereals), two points for the consumption of dairy products and fruit at least once a day, and finally, one point for the recommended weekly intake of potatoes, legumes, eggs, fish, white/red meat, and sweets, and for alcoholic consumption (wine and beer). A higher or lower observance to the recommendations was assigned from a score of 0 up to 24 . Anthropometric measurements, including body weight and stature, were assessed in accordance with the techniques described by Lohman et al. [14]. Body weight was recorded to the nearest $0.01 \mathrm{~kg}$ using a calibrated digital balance (SECA 813); height was measured to the nearest $0.1 \mathrm{~cm}$ with a portable stadiometer (PROMES, NL). The Body Mass Index (BMI) was calculated dividing the subject's weight in kilograms by the square of height in meters $\left(\mathrm{kg} / \mathrm{m}^{2}\right)$ and subjects were classified into three groups according to the WHO criteria [15]. Fat Mass and Fat Free Mass were calculated by skinfold thickness taken at four locations (biceps, triceps, subscapular and suprailiac) using Durnin and Womersley's equations [16]. Body fat was calculated using Siri's formula [17]. Skinfold thickness was measured on the non dominant side, in triplicate to the nearest $0.2 \mathrm{~mm}$ with a calibrated Holtain calliper (Holtain Ltd, UK) according to a standard procedure [14]. All measurements were made in each centre by the same skilled observer.

Blood samples were collected in EDTA or heparin containing tubes. After centrifuging at $3000 \mathrm{rpm}$ in refrigerated conditions the plasma was obtained and then stored at $-80^{\circ} \mathrm{C}$ until analysis. Aliquots of plasma were used to evaluate lipidic profile; precision and reproducibility were monitored using pooled human plasma or serum or a multi-parameter control for quantitative clinical chemistry determinations (ClinChem Control 1; Sentinel Diagnostics, Milan, Italy). Total cholesterol, high-density lipoprotein (HDL) cholesterol, low-density lipoprotein (LDL) cholesterol concentrations were measured using enzymatic tests (Sentinel Diagnostics, Milano, Italy). To evaluate the cardiovascular risk, the CVD risk score was used according to the CUORE algorithm [18]. The variables sex, age, cigarette smoking, systolic blood pressure, total and HDL cholesterol, the presence of diabetes and regular intake of antihypertensive drugs, made it possible to calculate the probability of experiencing a first major cardiovascular event (myocardial infarction or stroke) in the following 10 years. This score made is applicable to men and women who haven't had a previous cardiovascular event and provided that the risk factors are measured by adopting standardized methodologies.

The study was conducted in accordance to with the Declaration of Helsinki on the human trial performance and participants provided

Int J Clin Nutr Diet

ISSN: 2456-8171

IJCND, an open access journal Volume 6. 2020. 151 
Citation: Azzini E, Barnaba L, Intorre F, Ciarapica D, Verrascina M, et al. (2020) Food System Dynamics in Rural Environments and Health Benefits of the Mediterranean Diet. Int J Clin Nutr Diet 6: 151. doi: https://doi.org/10.15344/2456-8171/2020/151

Page 3 of 5

informed consent. The Ethics Committee of "Lazio 2" approved the procedure as well as the administration of this study.

\section{Statistical analysis}

Statistical analyses were made with StatSoft ${ }^{\circ}$ STATISTICA 8 for Windows (StatSoft, Italia Srl). A descriptive analysis was conducted to compute means with standard deviation; Student's t-test was used for the quantitative variables while the chi-square test was applied to compare qualitative variables. For all statistical analyses a significance level of $\mathrm{p}<0.05$ was used.

\section{Results}

The demographic and socio-economic assessment highlighted a very strong geographical isolation of restricted area. Demo-structural components showed a main characterization of depressed area with very small municipalities and important depopulation rates with few residents. Peripheral and marginalized characteristics were common in the studied municipalities, but remarkable differences were detected in the dynamics of local trade and consumption.

Socio-economic assessment within selected municipalities highlighted two clearly distinct areas. In the first area, including Montenerodomo, Pizzoferrato and Gamberale (Area 1), with higher presence of agricultural activities, had a supply farming system replacing the retail business, giving an important contribution in the distribution of fresh products (meat, eggs, cured meats, vegetables). In the second location, including Lama deiPeligni and Pennapiedimonte (Area 2) the link with agricultural activities was progressively reduced over the years and globalized production was more present as well as increased food demands and eating habits similar to those in "urban" municipalities.

By this socioeconomic evidence-based assessment, the nutritional survey proceeded in these two defined areas about eating habits, diet quality and cardiovascular disease on a sub-sample population at high risk, aged 35-70 years old. Selected subsamples included 99 healthy free-living volunteers (64 subjects in Area 1 and 35 subjects in Area 2). The general physical and body composition characteristics of the samples divided by area are shown in table 1 . The average BMI indicates the presence of an overweight state in both areas. In Area $1,35.9 \%$ are overweight and $42.2 \%$ are obese while in Area 2 these percentages were respectively $37 \%$ and $26 \%$ (data not shown). There were not significant differences in the physical characteristics among volunteers residing in the two areas except for weight $(p<0.05)$. However, in the Area 2, fat free mass $(\mathrm{kg})$ was statistically $(\mathrm{p}<0.01)$ lower than Area 1, and higher percentage in fat mass was observed in Area $2(38.2 \%$ vs $36.1 \%)$ even though no statistical differences were observed. Furthermore, the majority of the samples was married (70.0\%), especially in Area 2. Only 2\% were separated or divorced. Regarding the level of education, overall the first area showed a significant higher level of education $(92.1 \%$ vs 71.5$)$ respect the second location where the $20 \%$ of subjects had only primary level of education.

The results of local food products trade dynamics analysis by area (Figure 1) indicate that $54.3 \%$ and $44.3 \%$ of subjects, respectively for Area 1 and Area 2, have a mixed purchasing from large retailers (mainly dairy products) or small local shops (directly from the producer to the consumer). An average of $36.3 \%$ and $34.7 \%$ of subjects, respectively in the first and second areas, reported performing direct sales from

\begin{tabular}{|c|c|c|c|}
\hline & Area 1 & Area 2 & $\mathrm{p}$ \\
\hline & \multicolumn{2}{|c|}{$\begin{array}{l}\text { Physical characteristics (average } \\
\pm \text { d.s. })^{*}\end{array}$} & \\
\hline $\mathrm{n}^{\circ}$ & 64 & 35 & \\
\hline Age (years) & $51.02 \pm 9.2$ & $58.63 \pm 9.8$ & 0.000 \\
\hline Weight (kg) & $74.4 \pm 14.2$ & $68.5 \pm 13.1$ & 0.039 \\
\hline Height $(\mathrm{cm})$ & $159.7 \pm 8.5$ & $158.8 \pm 8.0$ & n.s. \\
\hline \multirow[t]{2}{*}{ Body Mass Index $\left(\mathrm{kg} / \mathrm{m}^{2}\right)$} & $29.1 \pm 4.9$ & $27.3 \pm 5.5$ & n.s. \\
\hline & \multicolumn{2}{|c|}{ Body composition (average \pm d.s.) } & \\
\hline Fat mass $(\mathrm{kg})$ & $26.9 \pm 7.3$ & $26.3 \pm 8.2$ & n.s. \\
\hline Fat mass (\%) & $36.1 \pm 6.5$ & $38.2 \pm 8.0$ & n.s. \\
\hline \multirow[t]{2}{*}{ Fat free mass $(\mathrm{kg})$} & $47.5 \pm 9.8$ & $42.2 \pm 9.2$ & 0.01 \\
\hline & \multicolumn{2}{|c|}{$\begin{array}{l}\text { General characteristics of the } \\
\text { sample }(\%)^{\varsigma}\end{array}$} & \\
\hline \multicolumn{4}{|l|}{ Marital status } \\
\hline Single & 23.8 & 11.8 & \multirow[t]{4}{*}{ n.s. } \\
\hline Married & 65.1 & 79.4 & \\
\hline Separated/divorced & 3.2 & - & \\
\hline Widowed & 7.9 & 8.8 & \\
\hline \multicolumn{4}{|l|}{ Educational level } \\
\hline Low & 1.6 & 20.0 & \multirow[t]{3}{*}{0.008} \\
\hline Medium & 92.1 & 71.4 & \\
\hline High & 6,3 & 8.6 & \\
\hline
\end{tabular}

Table 1: Physical characteristics and body composition of the volunteers by center.

Statistical analysis: ${ }^{*} \mathrm{~T}$ test; ${ }^{5} \chi^{2}$ test; level of significance. $\mathrm{P}<0.05$; n.s. $=$ not significant.

local producers with almost no intermediaries between consumer and producer. Only a small percentage of subjects (9\% - Area 1 and 21\% Area 2) used other purchasing food channels including convenience store where food products are occasionally acquired from local producers and in local areas during gastronomic expositions and fairs that promote local culinary heritage.

As shown in table 2, 98\% of people living in Area 1 eat a highly significant $(\mathrm{p}=0.011)$ amount of local products in comparison to those living in Area 2 (84\%) and their consumption was mainly determined by the awareness of the availability of such products that ensures the purchase of an authentic local product, with better organoleptic properties and a clear territorial identity of origin. However, all enrolled consumers had a scarce knowledge of the ability of biodiversity in supporting local farmers and local economies.

Results regarding the diet quality and cardiovascular risk are shown in table 3 . There is a statistically significant difference in the MDSS score $(p=0.002)$ between the two areas previously identified by the socio-economic evaluation. The results showed an average diet quality by MDSS out of a total of 24 points of $15.2 \pm 3.3$ for Area 1, higher than Area 2 (MDSS score: 12.2 \pm 4.6 ). In addition, a significant lower ( $\mathrm{p}=0.009)$ cardiovascular risk was observed in the first area as opposed to the second one, that present a higher percentage of subjects with probability of experiencing a first major cardiovascular event (myocardial infarction or stroke) in the following 10 years $(\mathrm{p}<0.05)$. Between areas, significant differences were present in the Cholesterol non-HDL $(\mathrm{p}<0.05)$, LDL $(\mathrm{p}<0.001)$ and LDL/HDL $(\mathrm{p}<0.0001)$ levels. 


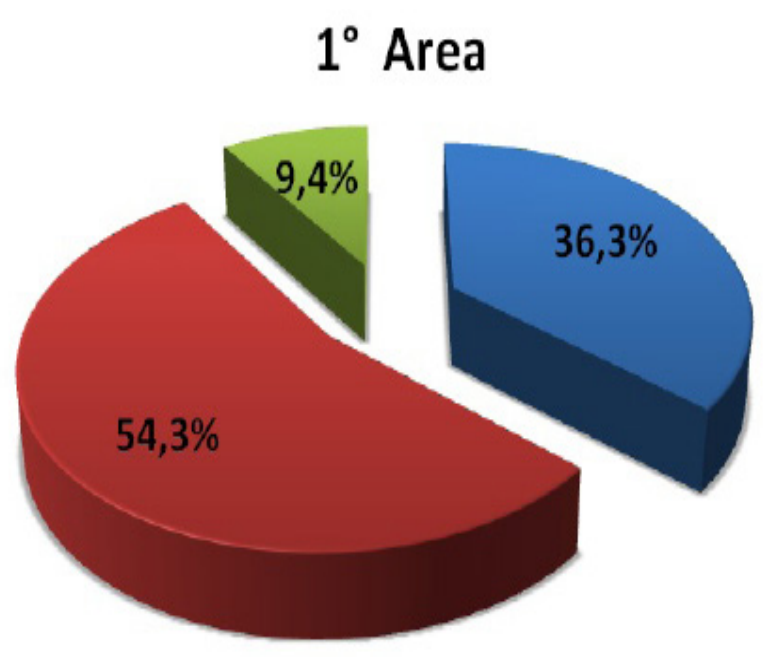

$\square$ direct $\square$ mixed Moccasionally

Figure 1: Food purchase channels for agro-food products by selected areas.

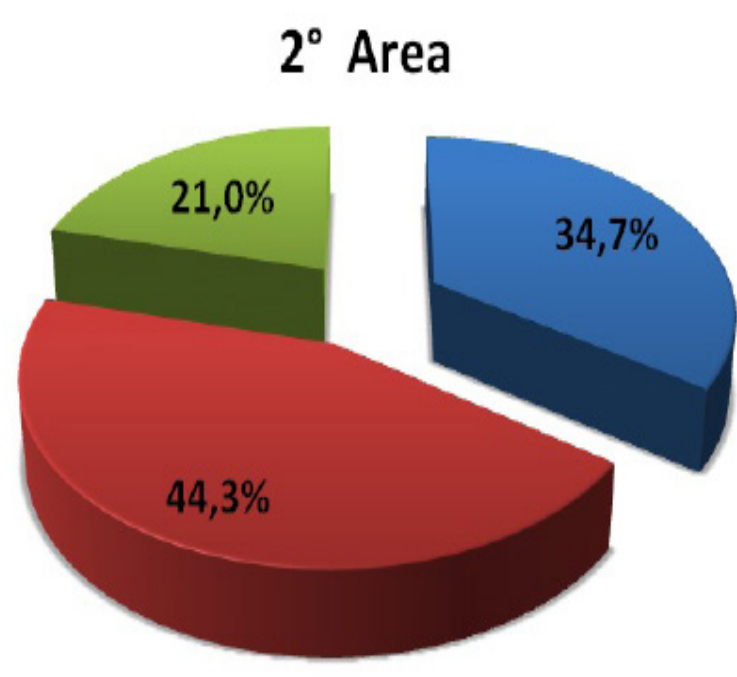

$\square$ direct $\square$ mixed $\square$ occasionally

\begin{tabular}{|c|c|c|c|}
\hline & Area 1 & Area 2 & $\mathrm{p}$ \\
\hline \multicolumn{4}{|l|}{ Do you eat local products? } \\
\hline Yes & 98.4 & 84.6 & \multirow[t]{2}{*}{0.011} \\
\hline No & 1.6 & 5.4 & \\
\hline \multicolumn{4}{|l|}{ Consumer's preferences } \\
\hline Organoleptic proprieties & 50.9 & 41.5 & \multirow[t]{2}{*}{ n.s. } \\
\hline Genuineness & 64.9 & 61.5 & \\
\hline
\end{tabular}

Table 2: Sample distribution (\%) by area for purchase and eating habits. Statistical analysis: $\chi^{2}$ test; level of significance. $P<0.05$; n.s. $=$ not significant.

\begin{tabular}{|l|l|l|l|}
\hline & Area 1 & Area 2 & $\mathrm{p}$ \\
\hline MDSS score & $15.2 \pm 3.3$ & $12.2 \pm 4.6$ & 0.002 \\
\hline CVD risk score (\%) & $3.3 \pm 4.5$ & $7.3 \pm 10.5$ & 0.009 \\
\hline Cholesterol (mg/dl) & $176.9 \pm 37.1$ & $185.5 \pm 32.8$ & n.s \\
\hline $\begin{array}{l}\text { Cholesterol non- } \\
\text { HDL(mg/dl) }\end{array}$ & $121.6 \pm 35.3$ & $134.2 \pm 32.6$ & 0.05 \\
\hline HDL (mg/dl) & $55.3 \pm 13.6$ & $51.3 \pm 10.6$ & n.s \\
\hline LDL (mg/dl) & $97.1 \pm 31.9$ & $118,6 \pm 34.9$ & 0.001 \\
\hline LDL/HDL & $1.82 \pm 0.64$ & $2.41 \pm 0.86$ & 0.0001 \\
\hline
\end{tabular}

Table 3: Diet Quality Index, CVD risk score and lipid profileby area. Statistical analysis: $\mathrm{T}$ test; level of significance. $\mathrm{P}<0.05$; $\mathrm{n} . \mathrm{s}$. $=$ not significant.

MDSS: Mediterranean Dietary Serving Score.

CVD: cardiovascular disease; HDL: High-Density Lipoprotein; LDL: low density lipoproteins.

\section{Discussions and Conclusions}

The main goal of this study has been to harmonize the different methodological frameworks proposed for assessing the influence of the dynamics of local trade and consumption, on the agricultural biodiversity and the Mediterranean eating habits of a population living in specific rural territory of Italy.
This multidisciplinary approach allowed for defining an area with a reasonable maintenance of local agricultural biodiversity as well as local agricultural techniques and production practices. Growing interest was found in rural sociology literature to consider culture as a fourth pillar of sustainable development $[19,20]$. These studies were primarily focused on the cultural dimension of food in the context of rural restructuring and rural sustainability, that it to say the cultural meaning of food. Our data underlined the close relationship among the local productive sectors, food consumption by local communities, markets and local supply chains. From the perspective of consumption behaviour analysis eating local was mainly determined by local awareness of products that ensure the purchase of authentic local produce with better organoleptic properties.

Several evidence-based researches give evidence of the ability of a Mediterranean-like dietary pattern to prevent various degenerative diseases and reduce the risk of cardiovascular incidents [21]. Our findings appear to underline the role of local foods in improving diet quality and their direct relation to the Mediterranean dietary pattern. The nutritional assessment in the two different socioeconomic areas highlighted a significant difference $(p=0.002)$ in the adherence to the Mediterranean food pattern by MDSS points (3 points, considering Area 1 vs Area 2). As in our previous observational study [22] the Mediterranean dietary pattern has been directly associated with significant amelioration of multiple risk factors, including a better cardiovascular risk profile. The subjects concerned in the previous study exhibited a higher adherence to MD and were consequently protected from lipid oxidation and oxidative stress. There is strong evidence in support of the assumption that lipid accumulation in the arterial wall will develop and progress into atherosclerotic lesions. The formation of foam cells represents the preclinical manifestation of atherosclerotic plaques and starts by modified circulating lowdensity lipoprotein levels (LDL) [23,24]. A cumulative analysis of 12 cohort studies by Sofi et al. [25] sustained that two points increase in the score for adherence to a Mediterranean diet determined a $9 \%$ reduction in mortality rates from cardiovascular diseases, a $6 \%$ reduction in incidence of or mortality from cancer and a $13 \%$ reduction in incidence of Parkinson's disease and Alzheimer's disease. Our findings conform to evidence presented to date. In fact, the greater the adherence to the Mediterranean diet style the more 
Citation: Azzini E, Barnaba L, Intorre F, Ciarapica D, Verrascina M, et al. (2020) Food System Dynamics in Rural Environments and Health Benefits of the Mediterranean Diet. Int J Clin Nutr Diet 6: 151. doi: https://doi.org/10.15344/2456-8171/2020/151

Page 5 of 5

significantly can one reduce the percentage of CVD risks by at least $3 \%$ as shown in the first Area as opposed to Area $2(\mathrm{p}=0.009)$. A recent update of the previous meta-analysis by Sofi et al. [26] reinforces the strong association between reduced risk of the incidence of main chronic degenerative diseases and the attainment of at least 2 points in adherence score to the Mediterranean diet. Additionally, the unhealthy trend in the levels of second area could indicate and confirm the high risk in cardiovascular risk.

\section{Conclusions}

This pilot investigation confirmed the role of the socioenvironmental and market dynamics in determining the populationlevel dietary patterns and eating behaviours in the prevention of human health. As suggested by EAT-Lancet Commission [27] achieving healthy diets from sustainable food systems for everyone will require substantial shifts towards healthy dietary patterns, large reductions in food losses and waste, and major improvements in food production practices. Our research seems to support this statement. A multidisciplinary approach should be encouraged to better underline the importance of local biodiversity protection and the impact of proper nutritious habits. For the future, more joint actions should be planned among different institutional entities with in-depth expertise.

\section{Author's Contributions}

All authors have made substantial contributions to all section of the manuscript and have given final their approval of the version to be published.

\section{Funding}

This study was supported by the Italian Ministry of Agricultural, Food and Forestry Policies in the framework of the TERRAVITA "Biodiversity, Territory and Nutrition: the sustainability of Italian agro-food" project D.M. 25870/7303/2011 of 2/12/2011

\section{Competing Interests}

The authors declare that they have no competing interests.

\section{References}

1. Ruben R, Verhagen J, Plaisier C (2019) The Challenge of Food Systems Research: What Difference Does It Make? Sustainability 11: 171

2. Food and Agriculture Organization of the United Nations (2012) Sustainable diets and biodiversity: directions and solutions for policy, research and action. Rome, Italy: FAO and Bioversity International.

3. Reynolds CJ, Buckley JD, Weinstein P, Boland J (2014) Are the dietary guidelines for meat, fat, fruit and vegetable consumption appropriate for environmental sustainability? A review of the literature. Nutrients 6: 22512265.

4. Vieux F, Darmon N, Touazi D, Soler LG (2012) Greenhouse gas emissions of self-selected individual diets in France: Changing the diet structure or consuming less? Ecological Economics 75: 91-101.

5. Azzini E, Durazzo A, Polito A, Venneria E, Foddai MS, et al. (2012) Biodiversity and local food products in Italy. Proceedings of the International Scientific Symposium "Biodiversity and sustainable diets united against hunger". FAO Headquarters, Rome, Cap 4: 242-252.

6. Tuttolomondo A, Simonetta I, Daidone M, Mogavero A, Ortello A, et al. (2019) Metabolic and Vascular Effect of the Mediterranean Diet. Int J Mol Sci 20: 4716
7. Dontas AS, Zerefos NS, Panagiotakos DB, Vlachou C, Valis DA, et al. (2007) Mediterranean diet and prevention of coronary heart disease in the elderly. Clin Interv Aging 2: 109-115.

8. Bonaccio M, Di Castelnuovo A, Bonanni A, Costanzo S, De Lucia F, et al. (2014) Decline of the Mediterranean diet at a time of economic crisis. Results from the Moli-sani study. Nutr Metab Cardiovasc Dis 24: 853-860.

9. Polito A (2018) Rapporto di ricerca "Progetto TERRAVITA. Indagine multidisciplinare dei legami tra Territorio, Biodiversità, Nutrizione e Sostenibilità dell'agroalimentare italiano".

10. Pickering TG, Hall JE, Appel LJ, Falkner BE, Graves JW, et al. (2005) Recommendations for blood pressure measurement in humans: an AHA scientific statement from the Council on High Blood Pressure Research Professional and Public Education Subcommittee. J Clin Hypertens (Greenwich) 7: 102-109.

11. James GD, Gerber LM (2018) Measuring arterial blood pressure in humans: Auscultatory and automatic measurement techniques for human biological field studies. Am J Hum Biol.

12. Muntner P, Shimbo D, Carey RM, Charleston JB, Gaillard T, et al. (2019) Measurement of Blood Pressure in Humans: A Scientific Statement From the American Heart Association. Hypertension 73: e35-e66.

13. Monteagudo C, Mariscal-Arcas M, Rivas A, Lorenzo-Tovar ML, Tur JA, et al.(2015) Proposal of a Mediterranean Diet Serving Score. PLoS One 10: e0128594.

14. Lohman, TG, Roche AF, Martorell R (1988) Anthropometric standardization reference manual. Champaign, IL: Human Kinetics Books.

15. WHO (1995) Physical status: the use and interpretation of anthropometry Report of a WHO Expert Committee. WHO Technical Report Series 854 Geneva: World Health Organization.

16. Durnin JV, Womersley J (1974) Body fat assessed from total body density and its estimation from skinfold thickness: measurements on 481 men and women aged from 16 to 72 years. Br J Nutr 32: 77-97.

17. Siri WE (1993) Body composition from fluid spaces and density: analysis of methods. Nutrition 9: 480-491.

18. Palmieri L, Panico, Vanuzzo D, Ferrario M, Pilotto L, et al. (2004) La valutazione del rischio cardiovascolare globale assoluto: il punteggio individuale del Progetto CUORE. Ann Ist Super Sanità 40: 393-399.

19. Kivitalo M, Kumpulainen K, Soini K (2015) Exploring culture and sustainability in rural Finland. In Cultural sustainability and regional development: Theories and practices of territorialisation, eds.

20. Marsden T (2006) The road towards sustainable rural development: issues of theory, policy and practice in a European context. In Cloke P, Marsden T, Mooney P (eds.) Handbook of Rural Studies. SAGE.

21. Preedy VR, Watson RR (2014) The Mediterranean Diet: An Evidence-Based Approach Elsevier Science.

22. Azzini E, Polito A, Fumagalli A, Intorre F, Venneria E, et al. (2011) Mediterranean Diet Effect: an Italianpicture. Nutr J 10: 125.

23. Millán J, Pintó X, Muñoz A, Zúñiga M, Rubiés-Prat J, et al. (2009) Lipoprotein ratios: Physiological significance and clinical usefulness in cardiovascular prevention. Vasc Health Risk Manag 5: 757-765.

24. Summerhill VI, Grechko AV, Yet SF, Sobenin IA, Orekhov AN, et al. (2019) The Atherogenic Role of Circulating Modified Lipids in Atherosclerosis. Int J Mol Sci 20: 3561.

25. Sofi F, Cesari F, Abbate R, Gensini GF, Casini A, et al. (2008) Adherence to Mediterranean diet and health status: meta-analysis. BMJ 337: 1344.

26. Sofi F, Abbate R, Gensini GF, Casini A (2010) Accruing evidence on benefits of adherence to the Mediterranean diet on health: an updated systematic review and meta-analysis. Am J Clin Nutr 92: 1189-1196.

27. Willett W, Rockström J, Loken B, Springmann M, Lang T, et al. (2019) Food in the Anthropocene: the EAT-Lancet Commission on healthy diets from sustainable food systems. The Lancet 393: 447-492. 